\title{
Against the conditional correctness of scepticism
}

\section{Kaplan Hasanoglu}

To cite this article: Kaplan Hasanoglu (2016) Against the conditional correctness of scepticism, South African Journal of Philosophy, 35:1, 82-91, DOI: 10.1080/02580136.2015.1128241

To link to this article: http://dx.doi.org/10.1080/02580136.2015.1128241

\section{曲 Published online: 08 Mar 2016.}

Submit your article to this journal $\pi$

Q View related articles $₫$

View Crossmark data $\nearrow$ 


\title{
Against the conditional correctness of scepticism ${ }^{1}$
}

\author{
Kaplan Hasanoglu \\ Philosophy Department, Emmanuel College, Boston, USA \\ hasanogluk@emmanuel.edu
}

\begin{abstract}
Stroud has argued for many years that scepticism is conditionally correct. We cannot, he claims, both undergo a Cartesian-style examination of the extent of our knowledge as well as avoid scepticism. One reason Stroud's position appears quite plausible is the so-called 'totality condition' imposed for this kind of examination: as enquiring philosophers we are called upon to assess all of our knowledge, all at once. However, in this paper I argue that Stroud's apparent understanding of the totality condition is mistaken. Evidently, Stroud thinks that honouring the totality condition amounts to imposing the strong requirement that we initially assume that we do not know anything about external reality. However, there is a weaker requirement available: that we initially not assume that we know anything about external reality. I argue i) that the weaker conception of the totality condition is most suitable for the kind of philosophical examination that Stroud seems to have in mind; and ii) that according to this same conception, scepticism is not conditionally correct.
\end{abstract}

\section{Introduction}

Stroud continues to defend the position that scepticism is what he calls 'conditionally correct' ${ }^{2}$ In his view, a characteristically philosophical examination of our knowledge of external reality leads inevitably to the sceptical conclusion. Stroud sometimes calls it an 'external' examination. Described in condensed form, it is a detached assessment of the totality of our knowledge of mind-independent reality. ${ }^{3}$ Let me begin, then, with a brief (and somewhat incomplete) sketch of what an 'external' examination involves.

That knowledge of mind-independent reality is what is of interest here should come as no surprise, and the reader no doubt has at least an intuitive grasp of what it means to be that sort of reality. ${ }^{4}$ However, what does it mean to be a 'detached' enterprise? Here Stroud has in mind the following constraint: one must divorce the philosophical question of whether one knows something from the more practical question of when it is appropriate to say one knows something. In chapter 2 of The Significance of Philosophical Scepticism, Stroud (1984) grants that in plenty of everyday cases it would be conversationally inappropriate to deny that someone possesses knowledge regarding some mind-independent state of affairs. Nevertheless, he argues, in these same cases the denial is perfectly accurate - even according to ordinary usage of the term 'knowledge'. This is doubly instructive: not only does it help to explain what he means by a 'detached' enterprise; it also confirms that the conception of knowledge involved in an 'external' examination is supposed to be none other than

1 The main lines of thought found in this paper came about as a result of numerous fruitful discussions with both my dissertation adviser, Evan Fales, and Richard Fumerton. I am fortunate to count myself among those who owe a staggering intellectual debt to these men. To be sure, both continue to act as my chief interlocutors whenever I slip into the rabbit hole and find myself sparring, yet again, with 'the sceptic'.

2 For a concise characterisation of his position that scepticism is conditionally correct see, for example, Stroud (1984: pp. 23, 132, 195, 209).

3 See Williams (1996) for an in-depth discussion of each of the conditions involved in this sort of examination. The condensed characterisation of Stroud's position given above is owed to him: in particular (Williams 1996: p. 22). As Williams himself notes there, the above, condensed characterisation can be gleaned from the following places: (Stroud 1984: pp. 81-82, 209).

4 Of course, this is not to say that where precisely to draw the line between mind-dependent and mind-independent reality is obvious. 
the ordinary one. ${ }^{5}$ Of course, many would deny that a detached enterprise reveals what Stroud thinks it does. ${ }^{6}$ However, I will not take up that admittedly important issue here.

Next, in what sense is the project an assessment? Here I can gratefully follow the insightful analysis of Stroud's views offered by Michael Williams (1996), in his book, Unnatural Doubts. This aspect of an 'external' examination is reflected in the fact that what is examined is the extent of our knowledge. As Williams explains: 'The aim is not, or not just, to trace the origins or explain the causes of our beliefs, but to discover their basis or grounds, with a view to assessing their adequacy' (Williams 1996: p. 22). That is, to be concerned with whether we know anything at all about mind-independent reality, on this traditionally-oriented view, is to evaluate the epistemological merits of a certain class of beliefs. So, a positive assessment would amount to a satisfactory explanation of the fact that we possess some knowledge of mind-independent reality. As Stroud puts it, it would involve 'having good reason to accept something that would be an explanation [of our external world knowledge] if it were true' (Stroud 2000: p. 116). A negative assessment, on the other hand, is the realisation that no such explanation can be offered; in other words, it is the sceptical position.

Relying on the idea that the conception of knowledge at work in an 'external' examination is none other than the ordinary one, Stroud also argues as follows: it is part of that ordinary conception that a necessary condition for knowing something about mind-independent reality at a certain time involves knowing that one is not dreaming at that time. ${ }^{7}$ Put another way:

(1) I know that $p$ only if I know that I am not dreaming that $p$

(In this case, let ' $p$ ' stand for some claim concerning one's observable external surroundings.)

And here we arrive at one way of describing the heart of Stroud's position on scepticism. Evidently, (1)'s plausibility in particular is what does much of the work in bringing about its conditional correctness. We cannot, he thinks, consistently both grant (1) while engaging in an 'external' examination, as well as adequately explain why we have external world knowledge. For, in order to explain why we have such knowledge, we must explain why we know, or at least are able to come to know, that we are not dreaming. However, our only tool available for establishing that we are not dreaming is perceptual experience, and in Stroud's view perceptual experience is simply not up to the task. ${ }^{8}$

With this brief introduction of the other aspects of an 'external' examination now finished, in what follows I will focus on what it means to assess the totality of our knowledge. Stroud's position seems to be that assessing the totality of our knowledge requires us to initially assume that we do not know anything about external reality. However, as a result, he evidently ignores or would otherwise dismiss the viability of a weaker requirement: namely, that we not initially assume that we know anything about external reality. As I argue in the next section, this is crucial because if we understand totality in the weaker way, then scepticism is not conditionally correct. And, what is more, plausible reasons can be given for why we ought to adopt the weaker understanding. Such reasons are provided in the third section. So, in my view, Stroud is simply wrong. Scepticism is not conditionally correct.

\section{Cartesian questions regarding external world knowledge}

Roughly stated, assessing the totality of our knowledge requires us to assess all of what we take to be our knowledge of mind-independent reality, all at once. The reason this somewhat

5 In chapter 2 of The Significance of Philosophical Scepticism, Stroud rightly emphasises the importance of agreeing with this ordinary conception - otherwise it would not be clear that scepticism was a position of any interest.

6 For criticisms of Stroud's view on this matter, see Pappas (1991). For the classic discussion of how ordinary language philosophy can helpfully address the problem of scepticism, see Austin (1961). A useful discussion can also be found in Williams (1996: pp. 181-185).

7 Stroud argues that it is at least plausible to maintain that it is part of our intuitive concept of knowledge that in order to know that $p$, we must know to be false all scenarios known to be incompatible with knowing that $p$. See, for example, Stroud (1984: pp. 23-31, 39-82).

8 Granting (1), in order for us to know that we are not dreaming, Stroud argues, we must be able to perform some test which determines that we are awake and not dreaming. However, in order for this test to be of any help at all, we would have to already know that we are not merely dreaming that we are performing the test, and/or dreaming that it delivered us with a certain result. See Stroud (1984: pp. 20-23) for the argument. 
draconian-sounding condition is in place is quite simple. Traditionally-minded philosophers wish to provide an explanation of why anything we take to be external world knowledge is (in certain cases, at least) really knowledge. The would-be explanandum, then, is all of our external world knowledge. So, it would indeed seem problematic to make use of an external world knowledge claim in any explanation one offered. For, in that case, whatever one deployed would be part of the explanans. As a result, the proposed explanation would not be completely general, for it would not explain why one possessed the external world knowledge represented by the claim found in the explanans.

According to Stroud, how, then, does honouring the totality condition contribute to the conditional correctness of scepticism? What he says in the following passage will help to answer this question:

If we start by considering a certain domain of facts or truths and ask how anyone could come to know anything at all in that domain, it will seem that any other knowledge that might be relevant could not be allowed to amount to already knowing something in the domain in question. Knowledge of anything at all in that domain is what we want to explain, and if we simply assume from the outset that the person has already got some of that knowledge we will not be explaining all of it. Any knowledge we do grant to the person will be of use to him only if he can somehow get from that knowledge to some knowledge in the domain in question. Some inference or transition would therefore appear to be needed-for example, some way of going from what he is aware of in perception to knowledge of the facts he claims to know. But any such inference will be a good one, and will lead the person to knowledge, only if it is based on something the person also knows or has some reason to believe... That 'something' that he needs to know cannot simply be part of his evidential base, since it has to get him beyond that base. But it cannot go so far beyond that base as to imply something already in the domain in question either, since knowledge of anything at all in that domain is just what we are trying to explain. So it would seem that on either possibility we cannot explain with the proper generality how the kind of knowledge we want to understand is possible (Stroud 2000: p. 103). ${ }^{9}$

The following terminology will prove useful. Henceforth, by 'prior non-entailing knowledge', I will refer to any piece of knowledge that is known to fail, by itself, to entail any external world knowledge. Stroud's point, then, seems to be this. For the reasons discussed above, imposing the totality condition means that we cannot begin our attempt to explain why we possess external world knowledge by making use of an external world knowledge claim. Moreover, it seems clear that if we in fact possess external world knowledge, it must be delivered to us by our sense experiences. Next, and quite crucially, Stroud maintains that to initially make use of a claim that represents the sort of knowledge we get from sense experience, is to honour the just-mentioned requirement. In other words, since the sort of knowledge it gives us (he argues elsewhere) is compatible with the sceptical scenarios, sense experience delivers, at best, prior non-entailing knowledge. Now the task is clear. In order to explain why we possess external world knowledge, we must move by way of 'some inference or transition' from the prior non-entailing knowledge that sense experience gives us to some piece of external world knowledge. However, Stroud seems to be claiming that to deploy any additional knowledge claim that would then allow us to deduce that we have external world knowledge would be to violate the totality condition. In this case, his point seems to be, we would be explaining why we had external world knowledge by making use of a knowledge claim in the explanans which guaranteed that we already had it. So, we cannot offer a legitimate explanation that cites a piece of knowledge like that. On the other hand, combining the prior non-entailing knowledge we get from sense experience with an additional knowledge claim that only allowed us to then infer something compatible with the falsehood of some external world claim $p$, would not allow us to recover knowledge that $p \cdot{ }^{10}$ It seems, then, that we have a choice between either

9 For another statement of this idea, see Stroud (2000: pp. 5-6).

10 Nor, arguably at least, would it even allow us to recover reasonable belief in $p$ in any philosophically satisfactory way. For, briefly, if our sensory evidence is not substantial enough to entail any claim that $p$ concerning the external world, then granting that we lack additional $a$ priori reasons for thinking that such evidence makes $p$ probable, we will also not be in a position to rule out the radical sceptical position that $p$ is highly improbable given our evidence. However, this is admittedly controversial. So, for example, a recent and influential defence 
violating the totality condition, or else providing an explanation that is too weak to deliver an anti-sceptical result. Henceforth, this will be called 'the realist's dilemma'.

In order to both better understand as well as assess Stroud's position here, let us first adopt a meta-methodological perspective: one that peers down, so to speak, on the project of explaining why we know certain things about the external world. From this height, what looks to be the chief obstacle for the realist who wishes to refute the sceptic of the Cartesian sort we are concerned with here? (Henceforth, I will often leave the last qualification 'of the Cartesian sort we are concerned with here' tacit. ${ }^{11}$ ) The answer, by now, should be at least relatively clear. The chief obstacle is the view that sense experience only delivers us with prior non-entailing knowledge, combined with the restrictions imposed by the totality condition. To gain a better understanding of the nature and extent of the problem, then, we should now ask the following investigative question: how, more precisely, ought we to understand the totality condition? As we shall eventually see, related questions regarding what sort of knowledge sense experience provides us will also need to be addressed.

So, we need to ask, in effect: what constitutes obeying versus breaking the rules that the totality condition puts in place for an 'external' examination? And at this point we reach an important crossroads. It has already been shown that what the totality condition disallows is making use of an external world knowledge claim at any point in one's explanation of why one possesses external world knowledge. But, as was mentioned in the introduction, there are two quite different conceptions of the totality condition that might give rise to this constraint. According to one understanding, that condition amounts to the following: no constructive account of our external world knowledge can merely assume that one already has some piece of external world knowledge. So, according to this conception, we cannot make use of an external world knowledge claim at any point in our explanation because to do so is to merely assume that we already possess some external world knowledge. Clearly enough, however, honouring this condition is far different from honouring a requirement that gives the relevant negation much narrower scope. According to this much stronger rendering of the totality condition, one must assume for the examination in question that one does not know anything about the external world. So, just like the first conception, according to this stronger conception the reason why we cannot make use of an external world knowledge claim at any point in our explanation is because to do so is to merely assume that we possess such knowledge. But this conception of the totality condition imposes a further constraint. It also prevents one from making use of any claim other than prior non-entailing knowledge in any proposed explanation. We cannot make use of anything else because, to repeat, according to this conception we must assume that we do not already possess external world knowledge. Clearly, this amounts to the following constraint: we must assume that we only possess the sort of knowledge that will not allow us to deduce (or plausibly infer) that we have external world knowledge.

So, henceforth, let us call the stronger conception '(Narrow)' - so named because of the relatively narrow scope of the negation found within the statement of it - and render it as follows:

(Narrow): When assessing the extent of one's knowledge, assume at the outset that one does not know anything about external reality.

(Narrow) should be kept quite separate from the weaker requirement:

(Wide): When assessing the extent of one's knowledge, do not assume that one knows anything about external reality.

Which way should we construe the totality condition, for the purposes of better understanding Stroud's position? A related question is this: granting that Stroud claims that we cannot make use of an external world knowledge claim in the explanans, does he also restrict the sort of claim that we

of the contrary claim that the truth of certain external world claims is what best explains certain facts about our mental lives can be found in Vogel $(1990,2005)$. For what, in my view, is a convincing response, see Fumerton (2005).

11 By 'Cartesian sceptic' I mean, of course, the one who claims that proper philosophical reflection reveals that we know nothing about external reality. It should be obvious, then, that in this paper I do not intend to address the concerns of other kinds of sceptics such as, for example, the Pyrrhonian sceptic. 
can employ in any explanans to prior non-entailing knowledge? A lot of textual evidence suggests that Stroud adopts the stronger requirement. Consider the following passage:

The demand for a completely general understanding of knowledge in a certain domain requires that we see ourselves at the outset as not knowing anything in that domain and then coming to have such knowledge on the basis of some independent and in that sense prior knowledge or experience. That leads us to seek a standpoint from which we can view ourselves without taking for granted any of that knowledge that we want to understand (Stroud 2000: p. 120, emphasis added).

Assuming it can be taken at face value, this passage is quite revealing. Here, the requirement that we 'see ourselves at the outset as not knowing anything in [the] domain' in question seems to be a straightforward echo of (Narrow), as long as 'see ourselves' is taken to mean something close enough to 'assume'. Moreover, it also suggests that Stroud thinks that adopting (Wide), if anything, is a methodologically-imposed consequence that follows from adopting (Narrow). It is, evidently, adopting (Narrow) that 'leads us to seek a standpoint' that is itself characterised by (Wide). So, apparently, in his view (Narrow) is the more fundamental starting point. Here is another pertinent passage:

Suppose we abandon, or never reach, the idea or hope that our knowledge of the world around us is to be explained as being derived from some knowledge or experience that is not itself knowledge of the world around us - something that is 'prior to' or 'underdetermines' the knowledge we are interested in. What would we then need a philosophical 'theory of knowledge' for? (Stroud 2000: p. 7).

At this point, I need to introduce some additional terminology. By 'prior entailing knowledge', I will refer to knowledge that is not external world knowledge, but that is known to entail some piece of external world knowledge. According to Stroud, then, it seems that the task at hand must involve starting with some 'prior' knowledge that is 'not itself' external world knowledge, and then deriving external world knowledge from that prior knowledge. But, crucially, the last passage suggests that the prior knowledge that we must start with is not just any sort of knowledge that is not external world knowledge. More strongly, it evidently must be knowledge that also 'underdetermines' external world knowledge: in other words, it seems it must be prior non-entailing knowledge rather than prior entailing knowledge.

In several other places, Stroud expresses similar ideas. ${ }^{12}$ Evidently, then, Stroud ignores or would otherwise rule out (Wide) as an understanding of the totality condition. This is important, since an answer to which way we ought to construe the totality condition is absolutely crucial as long as we are indeed after an understanding of the extent of the trouble that the totality condition causes for the would-be epistemological realist. Having to honour (Narrow), after all, does (at least to me) make the task of legitimately recovering external world knowledge look to be an impossible enterprise, quite obviously subject to the realist's dilemma. If at the outset of my philosophical assessment I first grant that my sense experiences only allow me to know things like that it seems to me as if $p$, and I am also methodologically forced to only rely on more prior non-entailing knowledge, then it is easy to see that the only way I can pull the realist rabbit out of the hat is by first surreptitiously placing it there. In short, if we are adopting (Narrow), scepticism does look conditionally correct.

But notice that, by contrast, if we were adopting (Wide) as our conception of totality, relying on a choice piece of prior entailing knowledge could be considered a live option. After all, consistent with honouring (Wide) is the additional requirement that at no point in one's assessment can one assume that one only possesses prior non-entailing knowledge. Put in a clearer way, honouring (Wide) is compatible with also requiring that one not merely assume at the outset that one does not

12 See Stroud (2000: p. 103) cited in the main text above; and also (2000: pp. 104, 106-107, 109, 131-133). Interestingly, there is at least one place where Stroud may perhaps be interpreted as adopting (Wide) rather than (Narrow). In his essay 'Understanding Human Knowledge in General', Stroud writes: 'A philosophically satisfactory explanation of such knowledge must not explain some of the knowledge in the domain in question by appeal to knowledge of something else already in the domain' (2000: p. 116). What this seems to disallow is just that we appeal to some piece of external world knowledge when offering our explanation. Nothing is said here regarding whether appealing to prior entailing knowledge is also disallowed. 
know anything about the external world. Let us call the conjunction of (Wide) and this compatible negative requirement '(Wide+)'. Explicitly, it is the requirement:

i) That when assessing the extent of one's knowledge, one not assume at the outset that one knows anything about external reality.

ii) That when assessing the extent of one's knowledge, one not assume at the outset that one does not know anything about external reality.

Let us grant that as philosophers we are called upon to provide a completely general explanation of the extent of our knowledge. In that case, barring an adoption of (Narrow), it seems proper to adopt (Wide+) rather than merely (Wide). Stroud is no doubt right that making use of some external world knowledge claim in our explanation would not allow us to provide one of the proper level of generality. However, barring an adoption of (Narrow), it would seem proper to also disallow requiring that we only make use of the sort of knowledge claim that we know will not allow us to recover any external world knowledge. ${ }^{13}$ For, we might in this case be too hastily excluding something (prior entailing knowledge) that would allow us to provide an appropriately general sort of explanation. The crucial difference between (Narrow) and (Wide+), then, is that only the first requires assuming a perspective that already makes explaining the presence of external world knowledge methodologically impossible. It does this, in part, by understanding a 'completely general' explanation to be one that would disallow appealing to prior entailing knowledge. In contrast, the weaker constraint (Wide+) requires that an explanation only fail to make use of an external world knowledge claim in order to be 'completely general'. Appealing to prior entailing knowledge is quite allowed. So, this conception allows one to maintain, as a matter of methodology, a perspective defined by being neutral with respect to the question of whether or not external world knowledge might be recovered via prior entailing knowledge. Under (Wide+), then, the truth of scepticism is an open question. For this reason, if we adopt (Wide+), scepticism is not conditionally correct. I will develop this important point further, in the next section. I will also argue there that (Wide+) is far and away the more appropriate constraint for an 'external' philosophical examination. ${ }^{14}$

\section{Defending (Wide+)}

In order to explain why we ought to adopt (Wide+), we must first take another look at (1). So, consider the following instance of it:

(1*) I know that I have hands only if I know that I am not dreaming that I have hands.

The common view, of course, is that it becomes obvious after reflection on the matter that I do not know that I am not dreaming that I have hands. But what this common view fails to acknowledge is the dubiousness of the presuppositions about perceptual experience that give rise to it. ${ }^{15}$ To see this, suppose that the following view of perceptual experience was correct - what I will call a 'non-cognitive theory'. Suppose, that is, that veridical experience was most accurately understood as constituted by the skilful exercising of one's sense organs in a manner that allows one (ideally anyway) to felicitously comport one's body in one's immediately surrounding environment. ${ }^{16}$ On

13 I take it that the above explanation of the realist's dilemma shows well enough why requiring that we only make use of prior non-entailing knowledge in our explanation amounts to requiring that we only make use of what we know will not allow us to recover any external world knowledge.

14 This is under the assumption that, once we realise that (Narrow) ought to be rejected, it would be proper to adopt (Wide+) rather than merely (Wide).

15 A somewhat similar position is defended by McDowell. For a statement of his relevant views on perceptual experience, see, for example, McDowell (1982: p. 472). McDowell maintains that a proper understanding of perceptual experience (and perceptually-based knowledge) will allow us to notice that 'scepticism looks urgent only in the context of a visibly dubious assumption, which imposes a certain shape on the space of epistemological possibilities' (McDowell 1995: p. 888). See also (McDowell 1982: p. 479). This allows for 'quietism' with respect to the sceptical problem: we are justified in refusing to bother with the task of answering the sceptic. That is one place where McDowell and I differ. In my view, a proper understanding of the totality condition allows for the possibility of a constructive response to the sceptic, by way of a defence of a certain theory of perception.

16 Recently there have been defences of a position at least very close to what I am calling a non-cognitive theory. It is sometimes called a 'sensorimotor' or 'enactive' understanding of perceptual experience. It maintains that perceptual experience is partly constituted by skilful 
this view, for example, one of the primary functions of vision is to track the relative distance of environing macroscopic objects, in a manner that allows one (ideally) to comport one's body in the consequently appropriate manner. Among other things, vision allows you to avoid the madman who is coming at you with a knife; to keep your distance - if you can. The important feature of this sort of view is how it consistently rejects the claim that veridical experience is constituted by what might have failed in a radical fashion to 'match up with', 'be satisfied by', etc., what is really the case. On this view our 'plain' ${ }^{17}$ waking experiences and the world are tightly coupled; our experiences constitutively depend on the fact that we are behaviourally interacting with the mind-independent world at that time, in a manner that results in us being disposed to be sensitive to certain slight (or drastic) macroscopic changes that take place. The use of the term 'constitutively' here is crucial. On this view, it makes no sense whatsoever to say that we can have the 'plain' waking experiences we do, while also failing to behaviourally interact with the relevant mundane spatiotemporal objects. Therefore, there is no way we can have our 'plain' waking experiences while also interacting with the world in the way described by a brain-in-a-vat scenario, etc. Moreover, this sort of view rejects the claim (popular among optimistic epistemologists with more internalist leanings) that internal perceptual experiences, qua so-called 'states of seeming', serve as epistemologically efficacious intermediaries between oneself and mind-independent reality ${ }^{18}$ - this, in a word, is what is 'non-cognitive' about it. It should be clear how the latter sort of view coincides with the possibility for radical falsehood (unless, of course, one is adopting a naturalised version of it). If I think that my experiences themselves 'tell' me something about the world, then unless I adopt a naturalised perspective I am forced to admit that what they 'tell' me might continuously be misleading in some radical fashion. By adopting a position of a sort that implies the impossibility of radical mismatch, the non-cognitive theorist rejects these sorts of views as well. ${ }^{19}$ In order to avoid absurdity, of course, the non-cognitive theorist would be required to maintain that veridical experiences play some crucial role in our day-to-day epistemological practices. That is, no one can deny the cognitive significance of veridical experience (nor that our perceptual experiences, more generally speaking, sometimes play a role in engendering false beliefs). What the non-cognitive theorist will forcefully deny, however, is that veridical experience has this sort of significance while also being the sort of thing that might fail in a radical fashion to 'match up with' mind-independent reality.

This is no doubt a woefully under-described position. Nevertheless, I only bring it up here in order to point out its relationship with the philosophical position that we do not know we are not dreaming, a brain-in-a-vat, etc. For, consider any of the commonly given arguments for that position. Importantly, they all involve some premise to the effect that we cannot definitively rule out the possibility that we are dreaming, etc., on the basis of our ordinary perceptual experiences alone. Hopefully, despite its incompleteness, the above sketch indicates how claiming this depends on having already ruled out a non-cognitive theory. It amounts to assuming, without prior argument, that it is incorrect. So, for example, at the moment I know that I am having a 'plain' waking experience of (among other things) this computer. However, for all I know, a non-cognitive theory accurately characterises the metaphysical nature of this experience. So, for all I know at the moment, this computer itself (among other things) is playing a constitutive role in this experience. Thus (simplifying), it is possible that it is not possible that I am dreaming at the moment, a brain-ina-vat, etc. To think otherwise is quite clearly to merely dogmatically adhere to the belief that a non-cognitive theory is incorrect.

What about Stroud's argument for the claim that we do not know we are not dreaming? That argument runs as follows. In order for us to know that we are not dreaming, Stroud maintains, we

bodily activity. See Noë $(2004,2009)$ and Hurley (1998). Another proponent of something at least very much like this view is, famously, Merleau-Ponty (1945). Dewey also expresses views that I think are friendly to a non-cognitive theory; see, for example, Dewey (1917: pp. 64, 71); (1929: pp. 172-173).

17 Here I am employing Thompson Clarke's helpful use of 'plain'; see his (1972).

18 For discussion of this position, see Pryor (2000); Huemer (2001). A 'state of seeming' is understood to be a state that possesses representational content and also is such that it makes the subject prone to accept the content-related belief.

19 Of course, the naturalised versions of this sort of theory could not be rejected for this reason, since they in principle disallow the possibility of radical falsehood. 
must be able to perform some test which determines that we are awake and not dreaming. However, in order for this test to be of any help at all, we would have to already know that we are not merely dreaming that we are performing it, and/or not dreaming that it delivered us with a certain result (Stroud 1984: pp. 20-23). For this reason, attempting to perform such a test (e.g. pinching ourselves) will always be unhelpful, because we would have to then answer the question of whether we were merely dreaming that we were performing it.

But notice that for someone who reasonably accepts a non-cognitive theory, the very test of whether or not we are dreaming is without point. If that theory is true, for the reasons already discussed, we are already in a strong enough epistemic position to rule out the sceptical scenarios. Performing the test would be as pointless for us as would be the zoologist's analogous test for whether or not she is looking at a zebra rather than a cleverly painted mule. Because of the zoologist's strong epistemic position, she already knows just by looking (for example) that the animal in front of her is a zebra. So, the possibility that it is a cleverly painted mule is already ruled out, given her strong epistemic position. The point is this: for someone who reasonably adopts a non-cognitive theory, the dreaming possibility, etc., is similarly already ruled out.

Here, then, is perhaps the most important upshot of all of this: since these problems exist for the traditional arguments for scepticism, the philosophical question of whether we know anything about the external world must shift to the question of which theory of perceptual experience we ought to accept. The most striking effect of adopting (Wide+), then, is that it makes an 'external' examination become focused squarely on answering that metaphysical question. For, recall that (Wide + ) differs from (Narrow) in allowing one to cite prior entailing knowledge as a way of explaining why one possesses external world knowledge. Well, if a non-cognitive theory in particular can be adequately supported, it might be the sort of prior entailing knowledge needed to vindicate realism..$^{20}$ This, I think, provides the clearest picture of what it means to say that (Wide+) makes the truth of scepticism an open question, and hence why adopting it requires denying that scepticism is conditionally correct. Stroud is of course right in following Descartes by pointing out that if we know anything about the external world, it is only as a result of the sort of knowledge that sense experience provides us. However, he and Descartes are too quick in arriving at the conclusion that sense experience only gives us prior non-entailing knowledge. Instead, perhaps sense experience in fact allows us to know things like the antecedent of $\left(1^{*}\right)$. To argue, as I have, that we ought to abandon (Narrow) in favour of (Wide+), is to acknowledge this possibility, and hence the possibility that sense experience puts us in a strong enough epistemic position to rule out the sceptical scenarios. (Narrow) is the wrong conception of totality, then, because it requires that we only recover external world knowledge via prior non-entailing knowledge. This is to improperly deny or otherwise ignore the possibility that prior entailing knowledge exists, and hence that we might be able to arrive at the knowledge that a non-cognitive theory is true. So, it is to wrongly block that otherwise plausible potential route to a completely general explanation of the extent of our external world knowledge. (Wide+) is a superior conception of the totality condition, then, simply because it requires us to acknowledge the following independently recognisable possibility: if after undergoing a fair assessment of the matter it was discovered that a non-cognitive theory was far and away the most plausible one to accept, then realism might follow; in which case, one well-trodden road to scepticism would be forcefully blocked. Now, the emphasis on the 'ifs' and the 'mights' throughout this paragraph is of course deliberate, and is meant to underscore the modesty of this proposal. But for my purposes here, the modest proposal is more than enough. For, recall that to say, as Stroud does, that scepticism is conditionally correct, is to say that a properly philosophical examination makes scepticism inevitable. This position is false

20 Note that the claim that a non-cognitive theory of veridical experience is true is at least a candidate for prior entailing knowledge. It is not a claim about the external world. Instead, it is a metaphysical claim that could be employed to help explain how I am able to attain knowledge of the external world in the first place. It is in that sense that I think it is best described as 'prior' to any external world knowledge claim. If so, it avoids any problems that arise for the 'Moorean' response to scepticism (see Moore (1939)). And yet, if it is true, then since it clearly entails that I know that I am not dreaming, etc., it at least arguably entails that I know things like that I have hands, etc. Admittedly, however, if a non-cognitive theory is true, then which things in particular I know about the external world is a matter that requires subsequent investigation. Nevertheless, all I need at the moment is for it to be clear that if it is true, then I know certain things about the external world. That, I take it, is uncontroversial. 
just so long as the vindication of a non-cognitive theory, and hence also of realism, is a legitimate possibility under (Wide+). Notice, moreover, that since acceptance of a non-cognitive theory would in the just-imagined case be the end result of an 'external' examination, it would be quite inaccurate to claim that we were here defending realism by merely dogmatically assuming that that theory of perceptual experience is correct.

I do not mean to suggest that much of the above is lost on Stroud. As I have already pointed out, crucial to Stroud's own understanding of the conditional correctness of scepticism are what he calls 'Cartesian' views about the nature of perceptual experience. ${ }^{21}$ So, I think Stroud would agree with what I have said most recently, at least regarding the connection between scepticism/ realism and views about perceptual experience. He would also agree, I think, that one way to question the sceptical thesis is to question the 'Cartesian' conception of perceptual experience that seems to inexorably give rise to it. (See, for example, Stroud 2009: pp. 560-562). In light of this, given his belief in the conditional correctness of scepticism, it seems Stroud's response to my position would have to be something like this: the best we can do is point out that a conditional relationship exists between a non-cognitive theory and realism. ${ }^{22}$ In other words, it seems that Stroud would have to maintain that there can be no good philosophical reasons for accepting a non-cognitive theory. However, I can only further speculate as to what Stroud's basis would be for claiming this. Perhaps he thinks that there are strong independent reasons for accepting a 'Cartesian' conception of perceptual experience; reasons which should make us realise that we only in fact possess prior non-entailing knowledge. (See, for example, Stroud 2000: pp. 131-133). In that case, the problem is simply that this last move is too quick. Whether there are indeed convincing, non-question-begging arguments for a 'Cartesian' conception of perceptual experience is precisely what requires subsequent investigation. Perhaps, by contrast, a non-cognitive theory can be shown to be superior. On the other hand, it may be that Stroud (also) thinks that because a properly philosophical examination requires adopting (Narrow), we cannot make use of a claim like 'I know that a non-cognitive theory is true', since doing so would result in an explanation that is not completely general. Well, then the response is straightforward: so much the worse for (Narrow) and its consequent view of what it means to provide a 'completely general' explanation.

To sum up, here is the state of play: as we embark on an 'external' examination of the extent of our knowledge, for the reasons given we ought to be initially open to the possibility that we can come to know that a non-cognitive theory is true. But since coming to know that a non-cognitive theory is true amounts to possessing prior entailing knowledge, this means that we ought to be open to the possibility that we possess prior entailing knowledge. But this means we ought to adopt (Wide+), and hence reject both (Narrow) and the claim that scepticism is conditionally correct.

In closing, the following also bears mentioning: to show that a 'Cartesian' conception of perceptual experience is in fact somehow questionable is not yet to have provided a satisfactory philosophical explanation of the extent of our external world knowledge. Relatedly, to establish epistemological realism and hence defeat scepticism once and for all, it is obviously not enough to show that if a non-cognitive theory of perception is true, then epistemological realism follows. For we are still left with the question of whether we have good reason to believe the antecedent of that conditional.

But the goal of this paper was not to defeat scepticism once and for all. Instead, more modestly, the goal was to provide strong reasons for denying its conditional correctness. That is to argue for the denial of the following position: that granting that we are engaged in a properly philosophical examination of the matter, the sceptical conclusion that we know nothing of external reality is inevitable. So, it is to argue for the denial of the position that establishing epistemological realism is not so much something we have not yet done at any given point while we are engaged in that

21 Stroud writes, for example: 'if Descartes were right in representing our perception of objects in the way he does he would also be right in concluding that we can know nothing about the external world' (Stroud 1984: p. 132). In another place: 'if Descartes' description of our experience and its relation to the things around us were correct, we could never know whether there are external things' (ibid.: p. 195). See also Stroud (2009: pp. 560-562).

22 See Stroud (2000: pp. 118, 147-154) where he says things that suggest that this would indeed be his response to my position; however, there his relevant remarks pertain to why he questions the viability of an epistemological externalist response to scepticism. See also Stroud (2000: pp. 106-107). 
sort of examination, but rather is something we simply cannot do. But as long as we ought to adopt a methodological framework that grants what I think is quite clear-namely, that a non-cognitive theory might be able to be shown to be true after engaging in a fair assessment of the matter-that position is indeed simply false.

\section{References}

Austin, J.L. 1961. 'Other minds', in Philosophical Papers. Oxford: Oxford University Press.

Burge, T. 1986. 'Cartesian error and the objectivity of perception'. In: Pettit, P., McDowell, J. (eds), Subject, Thought and Content. Oxford: Oxford University Press. pp. 117-36.

Clarke, T. 1972. 'The legacy of skepticism', The Journal of Philosophy 69: 754-769.

Dewey, J. 1917. 'The need for a recovery of philosophy'. In: McDermott, J. (ed.), The Philosophy of John Dewey: Vols I and II. Chicago and London: The University of Chicago Press. pp. 58-97.

Dewey, J. 1929. The Quest for Certainty: A Study of the Relation of Knowledge and Action. New York: Capricorn Books.

Fumerton, R. 1995. Metaepistemology and Skepticism. Lanham: Rowman and Littlefield.

Fumerton, R. 2005. 'The challenge of refuting skepticism'. In: Steup, M., Sosa, E. (eds),

Contemporary Debates in Epistemology. Malden: Blackwell Publishing. pp. 85-97.

Huemer, M. 2001. Skepticism and the Veil of Perception. Lanham: Rowman and Littlefield.

Hurley, S. 1998. Consciousness in Action. Cambridge, Massachusetts: Harvard University Press.

Merleau-Ponty, M. 1945. The Phenomenology of Perception. Trans. Smith, C. London: Routledge 2002.

McDowell, J. 1982. 'Criteria, defeasibility, and knowledge', Proceedings of the British Academy 68: 455-79.

McDowell, J. 1995. 'Knowledge and the internal', Philosophy and Phenomenological Research 55: 877-93.

Moore, G.E. 1939. 'Proof of an external world', in Philosophical Papers. London: Allen \& Unwin. pp. 127-150.

Noë, A. 2004. Action in Perception. Cambridge, Massachusetts: MIT Press.

Noë, A. 2009. Out of Our Heads. New York: Hill and Wang.

Pappas, N. 1991. 'Knowing and saying I know', Philosophy 66: 487-502.

Pryor, J. 2000. 'The skeptic and the dogmatist', Nous 34: 517-549.

Stroud, B. 1984. The Significance of Philosophical Scepticism. Oxford: Oxford University Press.

Stroud, B. 2000. Understanding Human Knowledge. Oxford: Oxford University Press.

Stroud, B. 2009. 'Scepticism and the senses', European Journal of Philosophy 17: 559-570.

Vogel, J. 1990. 'Cartesian skepticism and inference to the best explanation', Journal of Philosophy 87: $658-666$.

Vogel, J. 2005. 'The refutation of skepticism'. In: Steup, M., Sosa, E. (eds), Contemporary Debates in Epistemology. Malden: Blackwell Publishing. pp. 72-84.

Williams, M. 1996. Unnatural Doubts: Epistemological Realism and the Basis of Scepticism. Princeton: Princeton University Press. 